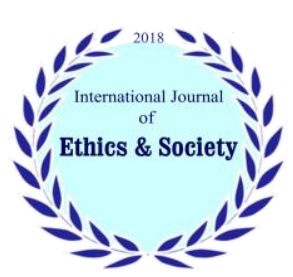

International Journal of Ethics \& Society (IJES)

Journal homepage: $\underline{\text { www.ijethics.com }}$

Vol. 3, No. 3 (2021)

(Original article)

\title{
Study of the Effects of Managers' Professional Ethics on the Decision-Making Strategies: Moderator Role of Information Management Systems Capacity
}

\author{
Saeid Khayat Moghadam
}

Dept. of Public Administration, Faculty of Management Accounting, Islamic Azad University, Mashhad Branch

\section{Abstract}

Background: Ethical principles applied in organizations can broaden individual and corporate priorities beyond profit and shareholder enrichment. Ethical factors may influence leaders to make sound decisions to protect the organization from unethical behavior. The present research seeks to investigate the effects of managers' professional ethics on decision-making strategies regarding the role of the capacity of information management systems capacity in the managers of Islamic Azad University, Mashhad Branch.

Method: The present study is a descriptive-comparative study. The population in this study is determined to be a group of managers of Islamic Azad University, Mashhad Branch concluding 111 individuals. Data collection was conducted through questionnaires of professional ethics, decision-making strategies, and information systems capacity. The sample size was obtained utilizing the Cochran's formula and the data collection was performed using simple stratified random sampling method. SPSS and Smart PLS were used to analyze the statistics and the structural equation modeling method was used to answer the research hypotheses.

Results: The results showed that managers' professional ethics has an impact on decision-making strategies, but information systems capacity does not modify the influence of managers' professional ethics on decisionmaking strategies.

Conclusion: Professional ethics affects decision-making strategies at Mashhad Islamic Azad University. Therefore, observance of ethical issues in the organization, especially in dealing with managers with employees is a need and respect should always be considered so that the employees feel more committed to their work and organization.

Keywords: Professional ethics, Decision-making Strategies, Information systems capacity, Management

*Corresponding Author: Email: skhayatmoghadam@gmail.com

Received: 10 May 2021

Accepted: 20 Jul 2021

Copyright: (C) 2021 Khayat Moghadam S. Published by Iranian Association of Ethics in Science and Technology This article is an open access article distributed under a Creative Commons Attribution-Noncommercial 4.0 International License. (https://creativecommons.org/licenses/by-nc/4.0/). 


\section{Introduction}

The decision-making strategy is a way by which the managers of the organization develop the organization's predetermined goals and the also apply these ways in order to accelerate the achievement of these goals (1). Today, large and medium-sized organizations face many opportunities and threats in the path to perfection, some of which are challenging and their management needs to obtain a strategy of decision-making.

The correctness of which can lead to significant leaps in the direction of the organization's way and the incorrectness of the decision made could lead to a slowdown in the organization's progress in the modern world of speed or even the destruction of the organization (2). The decision-making is a process that leads to the selection of the appropriate method and procedure (3). Today, small and large organizations are confronted with far more complex situations. Issues such as intensive competition, economic fluctuations, daily crises in international relationships, rapid technological advances in most areas, greater sensitivity of the human factor in the organization and many other issues has made managing organizations more difficult than before, so that the management has changed the position of "a decision for a lifetime" to "a decision for a day". factors in the organization (4). When organizational theorists speak of organizational decisionmaking, they refer to a variety of decision-making processes that are adopted at all levels as well as in all organizational units.

The ethical characteristic of the leader is uniquely important in that it is expected that such characteristics will have a positive effect on organizational behavior (5). So far, research has shown that ethical leadership predicts outcomes such as organizational citizenship behavior (OCB), organizational commitment (OC), and perceived leadership effectiveness $(6,7)$. Therefore, understanding the personality traits associated with ethical leadership is important because of the ability of the leader to influence the behavior of the staff and the organization. Recently, a number of studies have included personality traits, and features of the ethical behavior of the leader, and embody a significant empirical basis for arguing that personality traits are important in predicting the phenomenon of ethical leadership (8; 9 and 10). Today, the emphasis on ethical issues has been expanding and one of the effective ways of applying moral debates and implementing ethical issues in society is paying attention to ethical issues in decision-making or ethics in management science (11). Ethics and ethical behavior advert more to general principles such as honesty, integrity, and morals. However, the code of professional conduct, is a specific set of rules set by the governing bodies. Although the rules set out by diverse bodies around the world are each unique, some rules are universal (12). Professional ethics are behavioral principles set by individuals in a particular profession (13). Professional ethics are a set of ethical principles and criteria developed by organizations based on ethical patterns and all members of the organization are bound to adhere to these principles that guide their behavior (14). The observance of professional ethics represents the personality of the individual in the organization, and this is the professional ethics which puts the person in the desired shape both in society and among colleagues. Within the framework of this professional ethics, the role of people in the society is shaped, people become more intertwined, the communication between individuals increases, a series of ethical norms and behaviors is created among employees and managers, and also plays an important role in carrying out administrative and non-administrative activities that relate to the client. Professional ethics, in turn, stimulates many stimuli and eliminates many abnormalities. Some researchers believe that the functional values of a profession within an organization is related to professional ethics (15). The strategic decision of the managers can lead to organizational performance and behavior that is more consistent with the goals of the organization, because the executives' decisions reflect the goals of the organization, therefore, a strategic decision of the manager can the help the staff to achieve these goals better and easier. Another important issue, which is one of the requirements of the organization, is the issue of the 
capacity of information systems if the organization could significantly increase the capacity of its information systems, it would surely guarantee its success in the scientific and even economic fields. Compliance with professional ethics is one of the requirements for obtaining the organizational goals of Azad University of Mashhad and considering that Azad University of Mashhad trains of specialists, if they do not have the ability to establish professional ethics at the university, they cannot perform their responsibilities properly, so they cannot receive proper feedback. Recent studies have shown that the failure of information systems is mostly due to organizational and psychological issues rather than technology issues, the most important of which are organizational issues and information systems, which are endorsed by end-users due to their dissatisfaction. The attitude of most executives is that better performance of information systems alone will not lead to the satisfaction of end-users (16). Researchers in their study entitled "Investigating the relationship between professional ethics of managers and their decision making in listed companies," they concluded that there was a meaningful relationship between the managers' ethics and their decision making (17). A researcher conducted a study titled "Professional Ethics of Future Experiments: Qualitative Analysis of Physicians' decision-making" and concluded that professional ethics affect the quality of decision made by physicians (18). There are many methods and strategies available and the strategists and strategy designers, based on their knowledge of the organization's situation and circumstances, choose the methods to formulate the organization's strategy (19). Now, if the capacity of information systems increases in this organization, the employees and the organization can implement their predetermined plans and achieve their demands, so observing professional ethics either by the employees or the managers will solve many problems. Regarding the above mentioned, we seek to answer two questions: Do professional ethics of managers influence decision-making strategies? Does the capacity of information management systems modulate the relationship between professional ethics of managers on decision-making strategies?

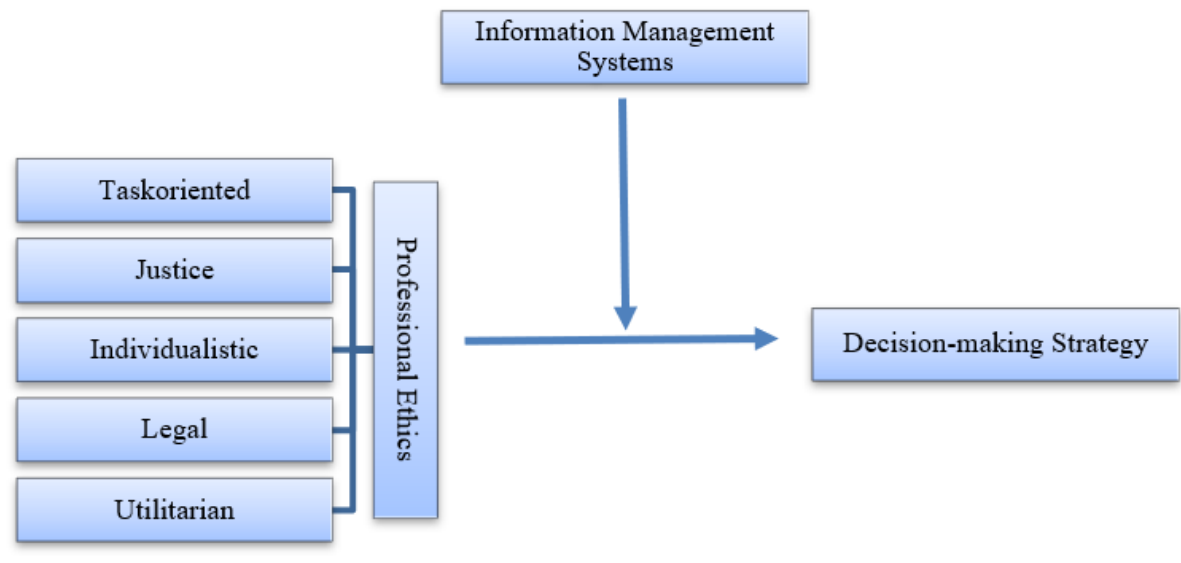

Fig 1: Conceptual model

\section{Material \& Methods}

This research is descriptive-correlation in terms of purpose, application, type and analysis. The statistical population in this study is the managers of the Islamic Azad University of Mashhad including 86 individuals selected by simple random sampling method as statistical sample. The instruments used in this study include Bahagir Medical Ethics Questionnaire (2011), which has 37 questions and measures the components (Utilitarian ethics, Individualistic Morality task-oriented ethics, Ethics of justice, Legal ethics), Aldi (2006) decision-making strategy questionnaire containing 18 questions and 
measuring two components (rationality, emotionality), and the questionnaires of information systems capacity, which contain 9 questions. The type of scale used is graded based on the Likert scale and the reliability of the mentioned questionnaires is shown in Table 1.

\section{Table 1: Reliability of research questionnaires

\begin{tabular}{|l|c|}
\hline Questionnaire & $\begin{array}{l}\text { Cronbach's Alpha } \\
\text { Coefficient }\end{array}$ \\
\hline professional ethics & 0.879 \\
\hline information systems capacity & 0.941 \\
\hline decision-making strategies & 0.931 \\
\hline
\end{tabular}

Structural Equation Modeling method was employed utilizing PLS software to investigate the relationship among the independent, moderating, and dependent variables, and determining the effects of each of them on the other.

\section{Results}

After collecting the research data and verifying the validity and reliability of the research instruments, analyzing the data of the questionnaire, we can use the statistical tests.

In this research, structural equation model was used benefiting PLS software to test the hypothesis and the goodness of fit of the research model. If the goodness of fit of the structural equation model is appropriate, after fitting the model, using the estimated regression coefficient significance test, we examine the existence or absence of a significant relationship between professional ethics, decisionmaking strategies, and the role of information systems capacity moderator.

Main research hypothesis
Main hypothesis: Professional ethics affect the decision-making strategy.

The null hypothesis of this test suggests that there is no significant relationship between professional ethics and decision-making strategies, and the opposite hypothesis suggests that professional ethics have an impact on decision-making strategies. The statistical assumptions of this test are as follows:

$$
\left\{\begin{array}{l}
H_{\circ}: b_{1}=0 \\
H_{1}: b 1 \neq 0
\end{array}\right.
$$

If the test of the significance of the independent variable regression coefficient, namely, the professional ethics ( $T$ test), indicates that this coefficient is significant, it is concluded that the professional ethics variable has a meaningful relationship with the decision-making variable, and depending on the coefficient being positive or negative the relationship can be direct or reciprocal. Accepting or rejecting the significance of the coefficient is decided based on the amount of the $\mathrm{T}$ test statistic. If the estimated T statistic is greater than 1.96 or less than -1.96 or the absolute value of the $\mathrm{T}$ statistic is greater than 1.96, indicates the accuracy of the impact of the structures with a confidence of $95 \%$, and if the value of these statistics is between -1.96 and 1.96, or the absolute value of the T statistic is less than 1. 96, the impact of the structures is rejected. In this research, structural equations using PLS method and software have been used to investigate the research hypotheses.

\section{Model fitting indicators}

Before fitting the model, we examine the model fitting indicator. If the fitting indicators of the model are appropriate, it means that the model is suitable for fitting. In Table 2, the fitting indicators of the model are described by the PLS method.

Table 2: Indicators of fitting quality assessment

\begin{tabular}{|c|c|c|c|c|c|}
\hline Variable & Community & $\mathbf{R} 2$ & CV RED & CV COM & GOF \\
\hline \multirow{3}{*}{$\begin{array}{c}\text { Decision Making } \\
\text { Strategies }\end{array}$} & \multirow[t]{3}{*}{0.54} & 0.02 & -0.001 & 0.47 & 0.1 \\
\hline & & Less than 0.19 & Less than 0.02 & Positive & $\begin{array}{l}\text { More than or Equal } \\
\text { to } 0.01\end{array}$ \\
\hline & & Poor Prediction & Poor & $\begin{array}{c}\text { The Measurement Model Enjoys } \\
\text { Appropriate Quality }\end{array}$ & Poor Quality \\
\hline
\end{tabular}


Regarding the table on the model indicators, it can be seen that the R2 and CV RED indicators show that the independent variable i.e., professional ethics, are poor in predicting the dependent variable of decision-making strategies. CV COM indicator is positive, which indicates the appropriate quality of the decision-making strategies measuring model. The GOF indicator shows that the proposed structural equations model is of poor quality and it can be said that the structural equations model has a poor quality.

Fitting Model Results

The results of fitting the structural equation model are shown in Fig. 2, Table 3.

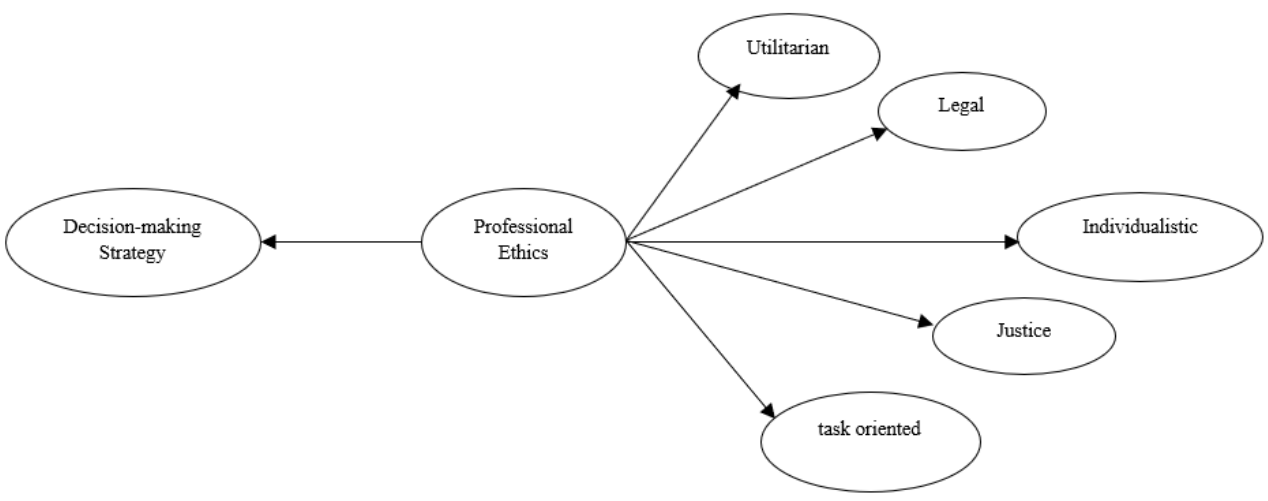

Fig. 2: The results of the fitting of the structural equation model and the absolute value of the statistics of the T-paths

Table 3: The results of fitting the structural equation model

\begin{tabular}{|c|c|c|c|c|c|c|}
\hline $\begin{array}{c}\text { The absolute magnitude of } \\
\text { the test statistic }\end{array}$ & $\begin{array}{c}\text { The standard } \\
\text { error }\end{array}$ & $\begin{array}{c}\text { Standard path } \\
\text { coefficient }\end{array}$ & $\begin{array}{c}\text { Path } \\
\text { coefficient }\end{array}$ \\
\hline $2 / 529$ & $0 / 060$ & $0 / 166$ & $0 / 151$ & $\begin{array}{c}\text { Professional } \\
\text { Ethics }\end{array}$ & $\begin{array}{c}\text { Decision-making } \\
\text { Strategies }\end{array}$ \\
\hline
\end{tabular}

The main hypothesis: Professional ethics affects decision strategies

With regard to the absolute magnitude of the $\mathrm{T}$ statistic related to the professional ethics variable $(529 / 2)$, which is more than 1.96 , it follows that the null hypothesis in significance test of professional ethics variables suggest that the coefficient is not meaningful and with 95\% confidence, it can be said that: Professional ethics affect decisionmaking strategies

Also, considering the estimated coefficient for this variable of 0.151 , which is positive, one can say that there is a direct and significant relationship between professional ethics and decision-making strategies and by increasing the amount of ethics, decision-making strategies increase. Also, according to the estimated standardized error rate of $5 \%$ error rate, we can say:

As professional ethics grows, the capacity of information systems increases by a factor of 166 A study on the moderation of the capacity of information systems in influencing professional ethics on decision-making strategies The role of moderating the information systems capacity in the impact of professional ethics on the decision-making strategies of the above model has been fitted in Amos software. If the fit of the structural equation model is appropriate, after fitting the model, using the estimated regression coefficient significance test, we examine the role of moderating the capacity of information systems in 
the impact of professional ethics on decision strategies. If the coefficient of interaction between the variable of professional ethics and decision-making strategies is not significant, it is shown that the capacity of information systems does not modify the impact of professional ethics on decision-making strategies, and if the coefficient of this variable is meaningful, this suggests that the variable of the capacity of information systems in the impact of professional ethics on decision-making strategies has a moderating role. The statistical expression of the above hypotheses is as follows.

The capacity of information systems does not modify the impact of professional ethics on decision-making strategies.
The capacity of information systems modifies the impact of professional ethics on decision-making strategies.

$$
\left\{\begin{array}{l}
H_{\circ}: b_{3}=0 \\
H_{1}: b_{3} \neq 0
\end{array}\right.
$$

Deciding whether to accept or deny the coefficient is made based on the T test.

Model fitting indicators

The indicators related to the quality of the above model are reported in Table 4.

Table 4: Indicators of Fitting Quality Assessment

\begin{tabular}{|c|c|c|c|c|c|}
\hline Variable & Community & $\mathbf{R} 2$ & CV RED & CV COM & GOF \\
\hline \multirow{3}{*}{$\begin{array}{l}\text { Decision Making } \\
\text { Strategies }\end{array}$} & \multirow{3}{*}{0.54} & 0.08 & 0.001 & 0.47 & 0.21 \\
\hline & & $\begin{array}{l}\text { Less than } \\
0.19\end{array}$ & $\begin{array}{l}\text { Less than } \\
0.02\end{array}$ & Positive & Equal to 15 \\
\hline & & $\begin{array}{l}\text { Poor Predic- } \\
\text { tion }\end{array}$ & $\begin{array}{l}\text { Poor Predic- } \\
\text { tion }\end{array}$ & $\begin{array}{l}\text { The Measurement Model Enjoys Appropriate } \\
\text { Quality }\end{array}$ & $\begin{array}{l}\text { Average } \\
\text { Quality }\end{array}$ \\
\hline
\end{tabular}

According to the table for the model indicators, the R2 and CV RED indicators indicate that independent variables such as professional ethics, the capacity of information systems and their interaction in predicting the dependent variable of decision strategies is poor. Also, CV COM indicator is positive for decision-making strategies, which indicates that the quality of the model for measuring decision-making strategies is appropriate. The GOF indicator also shows that the proposed structural equation model has an average quality, and it can be said that the structural equation model has a moderate quality.

Model fit results

The results of fitting the structural equation model are shown in Table (5).

Table (5) results of fitting the structural equation model

\begin{tabular}{c|c|c|c|c|c|}
$\begin{array}{c}\text { The absolute magnitude } \\
\text { of the test statistics }\end{array}$ & $\begin{array}{c}\text { The } \\
\text { standard } \\
\text { error }\end{array}$ & Estimated & \\
\hline 2.970 & 0.146 & 0.435 & Professional Ethics & $--->$ & Decision-Making Strategies \\
\hline 0.510 & 0.380 & -0.157 & Information Systems Capacity & $--->$ & Decision-Making Strategies \\
\hline 0.881 & 0.329 & -0.290 & $\begin{array}{c}\text { Interaction Between Profes- } \\
\text { sional Ethics and Information } \\
\text { Systems Capacity }\end{array}$ & $--->$ & Decision-Making Strategies \\
\hline
\end{tabular}

The second main hypothesis: the capacity of information systems modifies the impact of professional ethics on decision-making strategies.
According to the absolute magnitude of the test statistics related to the variable of the interaction between professional ethics and the capacity of information systems (0.881) is less than 1.96 it is

24

Available at: www.ijethics.com 
concluded that the null hypothesis of the significance test of the coefficient of interaction between the two variables of professional ethics is confirmed by the decision-making strategies, and with $95 \%$ confidence, it can be said that:

The capacity of information systems does not modify the impact of professional ethics on decision-making strategies

\section{Discussion}

The analysis of the research hypothesis showed that professional ethics can predict decision-making strategies at Islamic Azad University of Mashhad, which, in comparison with the present research, a study entitled "the study of the relationship between professional ethics of managers on improving their decision-making in listed companies" and concluded that there is a significant relationship between professional ethics of managers and their decision-making which indicates the agreement of these two studies(17). Compared to the present study, also research entitled "leadership, ethics, and justice in strategic decision-making" and concluded that leadership, ethics, and justice were effective in strategic decision-making and there is a meaningful relationship between them which demonstrates the agreement of these two studies (20). in order to make the decisions of the organization sound and effective, and to be able to use it to address the problems of the organization, principle such as fairness, equality, justice, fair distribution of benefits, or the same rewards, impartial judgments, etc. should be taken into account (21). According to strengthen strategic decision-making, some critics should exist in the organization. People with different perspectives are difficult to reach agreement but it cannot be denied that decisions made on the basis of group decisions will be more comprehensive decisions and their effectiveness will be even greater for the organization. It is suggested that executives take into account the decisions made in the organization that are successful and bring many benefits to the organization and consider rewards that are somehow incentives for the staff. Research suggests that individuals in the organizations should be directed in such a way that they are not merely thinking about their own interests and that they care about their conscience, avoid hypocrisy and lies and cooperate in order to implement the decisions of the organization (22). Managers should be strict in choosing and implementing the plans that the considered for the organization. In order to make the right and creative decisions, it is necessary to consider different options for decision making since deciding between multiple choices is better than single-by-one reviews. In order to have efficient staff who can make the right decisions in the interests of the organization, it is necessary for them to be reminded that in any decision, they should consider conscientiousness and having the courage to make decisions necessary, and that they should take the responsibility of the consequences of the decisions made in the organization. In fact, the organization should respect the rights of others and be promising. also, the organization should give individuals the right to participate in decisionmaking in order to respect the interests of all individuals. Everyone has the right to protect their rights (23).

\section{Implications}

-Encouraging the units and employees to coordinate and integrate with each other in solving problems and achieving goals.

-Organizing in-service training programs to increase staffing skills and abilities, and place values, ideologies and culture as a permanent part of education.

-The ethical charter of the organization should be clearly and explicitly explained to all employees.

\section{Limitations of the Study}

Since the present study was extracted from a humanities research category, there were some factors that were beyond the control of the researcher and might have affected the findings, such as the personality traits of the employees, ethical atmosphere governing the organization, organizational culture, and fatigue caused by work in the staff.

Furthermore, the results of the current research are specific to the faculties of the Islamic Azad University of Mashhad and cannot be generalized to other organizations. 


\section{Research Problems}

- Lack of cooperation on behalf of some staff in completing the questionnaires;

- Failure to return the questionnaires on time;

- Difficult access to community members due to their organizational position

\section{Conclusion}

The overall result of this research showed that professional ethics affects decision-making strategies at Mashhad Islamic Azad University. Therefore, observance of ethical issues in the organization, especially in dealing with managers with employees is a need and respect should always be considered so that the employees feel more committed to their work and organization and, as a result, make the effort necessary to succeed and organize the success of the organization with the right decisions that will be made to advance the goals of the organization.

Therefore, the present paper examines the impact of professional ethics on decision-making strategies. To achieve this goal, it can be said there is a direct and significant relationship between professional ethics and decision-making strategies, and with the increase of professional ethics, decisionmaking strategies increase. Moreover, according to these results one can say that there is a direct and significant relationship between professional ethics and decision-making strategies. By increasing the amount of professional ethics, decision-making strategies increase

\section{Ethical Consideration}

In order to observe the principles of ethic as well as confidentiality of information and to ensure the confidence of respondents, the principle of confidentiality was adopted and the respondents were asked not to insert their names on distributed questionnaires in order to ensure their answers remain confidential.

\section{Conflict of Interest}

The authors declare that there is no conflict of interests.

\section{Acknowledgement}

I would like to thank all the staff of Islamic Azad University, Mashhad Branch and appreciate their help in answering the distributed questionnaires

\section{References}

1. Zahedi SH, Rafiee M (2011). Investigating the relationship between human resources strategy and ethical decisionmaking strategy with organizational performance: a study in research organizations of ministry of Jihad-e-agriculture. Public Management Researches, 4(13).

2. Ahmadian A (2010). Strategic decision-making in a nongovernmental organization. The $5^{\text {th }}$ International Management Conference, Tehran/ Iran. (In Persian).

3. Shirvani A, Mardani M (2011). Study of psychological factors in strategic decision-making by senior managers in the public sector according to Yong's cognitive style, a case study of the public sector organizations of Isfahan province. $8^{\text {th }}$ International Management Conference, Tehran/Iran. (In Persian).

4. Mollanazari M, Esmaeili Kia GH (2014). Identification of psychological characteristics affecting auditors' skills in conducting audit judgments. Accounting and Auditing Reviews, 78: 505-526. Doi: https://dx.doi.org/10.22059/acctgrev.2014.52906

5. Aghighi A (2019). Effect of personality characteristics' dimensions on ethical leadership. International Journal of Ethics \& Society (IJES), 1 (3).

6. Brown ME, Treviño LK, Harrison D (2005). Ethical leadership: A social learning perspective for construct development and testing. Organizational Behavior \& Human Decision Processes, 97:117-134. Doi: https://doi.org/10.1016/i.obhdp.2005.03.002

7. Mayer DM, Nishii L, Schneider B, Goldstein H (2007). The precursors and products of justice climates: group leader antecedents and employee attitudinal consequences. Personnel Psychology, 60: 929-963. Doi: https://doi.org/10.1111/j.1744-6570.2007.00096.x

8. Treviño LK, Brown M, Hartman LP (2003). A Qualitative investigation of perceived executive ethical leadership: perceptions from inside and outside the executive suite. Human Relations, 56: 5-37. Doi: https://doi.org/10.1177\%2F0018726703056001448

9. Walumbwa FO, Schaubroeck J. (2009). Leader personality traits and employee voice behavior: mediating roles of ethical leadership and work group psychological safety. Journal of Applied Psychology, 94(5): 1275. Doi: http://dx.doi.org/10.1037/a0015848 
10. Kalshoven K, Denhartog N, Deanne H (2010). Ethical leader behavior and big five factor of personality. Journal of Busimess, $\quad 100(2): \quad 349-\quad 366 . \quad$ Doi: https://doi.org/10.1007/s10551-010-0685-9

11. Sadeghi A (2013), Professional ethics in health management and observing patient rights. Medical Ethics, 24: 163 175.

12. Sepasi S (2019). Accounting Ethics. International Journal of Ethics \& Society (IJES), 1 (2) :23-29.

13. Gholampour M, Pourshafei H, Farasatkhah M, Ayati M (2020). Developing the moral codes of teachers in Islam: synthesis research based on the Roberts's model. International Journal of Ethics \& Society (IJES), 2 (3): 24-36. Doi: http://dx.doi.org/10.52547/ijethics.2.3.24

14. Amirkabiri A, Darouyian S (2011). interpretations of manager's professional ethics in small and medium-sized businesses. Ethics in Science \& Technology, (1): 84. (In Persian). Dor: http://dorl.net/dor/20.1001.1.22517634.1390.6.1.9.2

15. Beykzadeh J, Sadeghi M, Ebrahimpour D (2012). Effects of organizational factors on the of employees' professional ethics growth. Ethics in Science \& Technology, (2): 55. (In Persian).

Dor: http://dorl.net/dor/20.1001.1.22517634.1391.7.2.6.8

16. Elahi S, Taher M, HassanZadeh A (2010). Providing a framework for human factors relevant to the security of information systems. Lecturer in Human Sciences, 2 (1).

17. Kordeh S, Bahramian A (2015). Investigating the relationship between managers' professional ethics on improving their decision-making in companies accepted in listed companies. International Management Conference, Economics and Industrial Engineering, Tehran/ Iran. (In Persian).

18. Webster F, Wijer CH, Todd L, Grimshaw JM, Marshall A, Cook D, Maclennan G, Cuthbertson BH, Francis J (2016). The ethics of future trials: qualitative analysis of physicians' decision making. Available at: https://pubmed.ncbi.nlm.nih.gov/26739307/. Accessed: 28 May 2021. Doi: https://doi.org/10.1186/s13063-015-1137-8

19. Amiri A, Hemmati M, Mobini M(2010). Professional ethics, a necessity for the organization. Moral Knowledge, 1(4): 137-159.

20. Tatum, BC, Eberlin RJ (2007). Leadership, ethics, and justice in strategic decision making. Business Strategy Series, 8(4): 303-310.

Doi: https://doi.org/10.1108/17515630710684358

21. Hartog M (2007). Ethics and human resource management. Professional Journal of Business and Professional Ethics, 21: 8-1. Doi: https://doi.org/10.5840/bpej200221210

22. Bahagir H (2011). Investigating the relationship between professional ethics and organizational commitment. [MA thesis]. Karaj Teacher Training University, Karaj/Iran.

23. Bordbar B (2019). Professional ethics of marketing and sale in Iran. International journal of Business Management, 4 (1): 36-51. 